\title{
O Cooperativismo e a Gestão dos Riscos de Mercado: análise da fronteira de eficiência do agronegócio paranaense
}

\author{
Vilmar Rodrigues Moreira ${ }^{1}$, Christian Luiz da Silva², \\ Edmilson Alves de Moraes $^{3}$ e Roberto Max Protil $^{4}$
}

\begin{abstract}
Resumo: $\mathrm{O}$ artigo discute a gestão dos riscos de mercado do agronegócio, a influência das cooperativas agroindustriais nesta prática e avalia o portfólio de produção de commodities agropecuárias do Paraná, considerando a relação retorno-risco. Por meio da construção de uma fronteira de eficiência foi possível verificar quais seriam as mudanças necessárias no portfólio de produção do estado visando à eficiência econômica (definida neste trabalho como o trade-off entre retorno e risco). O artigo também avalia o grau de participação das cooperativas agroindustriais na produção dos itens considerados no modelo e quais as possíveis influências que este tipo de organização poderia exercer nas alterações das preferências de produção. Por meio de questionários e entrevistas com gestores de cooperativas foi avaliada a disposição em incentivar mudanças nos portfólios de produção das cooperativas e dos cooperados. Verificou-se que os principais motivos que influenciam as decisões sobre produção estão relacionados a aspectos econômicos e racionais, como foco estratégico da cooperativa e resistências dos cooperados. No contexto paranaense, os motivos relacionados a aspectos políticos ou sociais, inerentes às características organizacionais das cooperativas, não exercem influência significativa nas decisões sobre diversificação como instrumento para a gestão dos riscos de mercado.
\end{abstract}

Palavras-chaves: gestão de riscos de mercado, análise de portfólio, cooperativismo, agronegócio.

1 Matemático, doutor em Administração pela Eaesp/FGV, professor da Escola de Negócios da PUPCR. E-mail: vilmar.moreira@pucpr.br

2 Economista, pós-doutor em Administração pela USP, professor do doutorado em tecnologia e coordenador do mestrado em planejamento e governança pública da UTFPR.E-mail: christianlsilva@uol.com.br

3 Mestre e doutor em Administração pela FGV, coordenador e professor do programa de Mestrado e Doutorado do Centro Universitário da FEI. E-mail: edmilson@fei.edu.br

4 Agrônomo, doutor em Ciências Econômicas pela Georg-August-Universität Göttingen Alemanha, pós-doutor em Cooperativismo e Agronegócio pela Justus-Liebig-Universität Giessen - Alemanha, professor do Departamento de Economia Rural da UFV. E-mail: roberto.protil@ufv.br 


\begin{abstract}
This article discusses agribusiness market risk management, the influence of agribusiness cooperatives on this practice and assesses the portfolio of agricultural production commodities in the Brazilian state of Paraná regarding the risk-return relation. Through outlining an efficiency frontier, it was possible to determine the necessary changes to be carried out in the state production portfolio aiming at economical efficiency (defined, in the context of this work, as the trade-off between risk and return). The article also assesses the participation of agribusiness cooperatives in the production of items included in the model and the possible influences this type of organization could exert on changes addressed to economical efficiency. Through questionnaires and interviews with cooperative managers, it was possible to assess the cooperative willingness to motivate changes on their production and their member portfolios. It was also possible to verify that the main reasons influencing decisions on production preference changes are related to economical and rational aspects, such as cooperative strategic focus and member resistance. Reasons related to political or social aspects are inherent to the cooperative organizational characteristics, however, in the Paranás context these reasons do not exert significant influence on diversification decisions considered as market risk management tools.
\end{abstract}

Key-words: market risk management, portfolio analysis, cooperatives, agribusiness.

Classificação JEL: Q13, G32.

\section{Introdução}

A competitividade no agronegócio exige dos produtores uma permanente revisão da maneira como são planejadas e organizadas suas atividades, incluindo desde questões operacionais do planejamento produtivo até o relacionamento com seus fornecedores e clientes. A competitividade promove novos processos de coordenação e organização, em que a livre negociação é substituída ou complementada por contratos, alianças ou até mesmo pela completa integração vertical (FAO, 2005). Por conta disso, os produtores rurais, sobretudo os menores, devem buscar associações, cooperativas, alianças ou outras formas de apoio para se fortalecerem e conseguirem exercer algum papel que seja efetivamente significativo (GUILHOTO, FURTUOSO e BARROS, 2000). No nível rural as organizações associativas podem ser caracterizadas por vários tipos de estruturas. As cooperativas, por exemplo, são casos de organizações estruturadas que podem alcançar altos níveis de integração vertical.

No Brasil as cooperativas agroindustriais possuem uma alta representatividade e participação na produção e comercialização de produtos agropecuários. Elas absorvem grande parte da produção agropecuária e influenciam decisões de produção e comercialização. As cooperativas participam com $41,53 \%$ da receita total gerada no agronegócio e os estabelecimentos que estão associados a alguma cooperativa apresentam rentabilidade maior que a média nacional: Brasil - R\$ 123/ha; não cooperados - R\$ 92/ha; cooperados - R\$237/ha. A participação das cooperativas na produção de alguns itens também é representativa: milho - 17\%; café - $28 \%$; soja - $30 \%$; suínos - 32\%; algodão $39 \%$; leite - 40\%; trigo - 62\% (OCB, 2007). A participação das cooperativas no agronegócio posiciona estas organizações como importantes players do setor e, por conta disso, as cooperativas e suas especificidades não devem ser ignoradas em estudos que visam melhorias na gestão do agronegócio, sobretudo se o interesse for relacionado à eficiência econômica.

A eficiência econômica é definida, no contexto deste trabalho, como sendo o trade-off entre retorno e risco, ou seja, a combinação de atividades na qual o produtor obtém a máxima receita em determinados níveis de risco aceitáveis - medidos pela variabilidade da renda e que definem a principal fonte dos riscos de mercado. Na produção rural a desconsideração dos riscos leva a decisões que não possuem aderência à 
prática dos produtores. O objetivo da melhor gestão dos riscos, por parte dos produtores rurais e cooperativas, é de especial interesse a todos os envolvidos em atividades do agronegócio.

Todavia, nas cooperativas agroindustriais os recursos econômicos e sociais devem ser investidos de forma alinhada aos objetivos cooperativistas. Neste contexto surge a preocupação em harmonizar objetivos econômicos com a doutrina cooperativista. Segundo Antonialli (2000), um dos grandes desafios das cooperativas é conseguir equilibrar os interesses econômico, social e político dos seus membros. O interesse econômico está relacionado ao crescimento da cooperativa e dos empreendimentos dos cooperados. O interesse social se refere aos serviços e benefícios que se esperam da cooperativa quando alguém se associa a ela. $O$ interesse político normalmente leva a disputas internas pelo poder e representatividade da cooperativa perante a comunidade. A incapacidade da cooperativa em equilibrar esses interesses pode levar à falta de competitividade e a situações gerenciais complexas. Este quadro de referência levanta questões pertinentes a respeito da capacidade da cooperativa em sobreviver em um ambiente de globalização e competição e, ao mesmo tempo, harmonizar a racionalidade política (doutrina cooperativista) com a racionalidade econômica (eficiência econômica).

Inicialmente são apresentadas considerações sobre os riscos no agronegócio e na gestão das cooperativas. Com o uso do modelo de análise E-V de Markowitz, como ferramenta de medição e avaliação dos riscos de mercado, foi analisado o portfólio de produção agropecuária do Paraná e gerada uma fronteira de eficiência que permitiu definir opções de portfólios eficientes. Utilizando estes portfólios seria possível otimizar a relação retorno-risco e, consequentemente, melhorar a gestão dos riscos de mercado no agronegócio do estado. Para tanto, seria necessário fazer alterações nos níveis de produção de alguns itens. Alguns aspectos sobre a viabilidade dessas alterações são discutidos quanto à possível influência que as cooperativas poderiam exercer e quais os principais motivos que influenciariam na não adesão às propostas. A análise dos motivos permite avaliar se a doutrina cooperativista poderia exercer algum tipo de influência na gestão dos riscos de mercado do agronegócio por meio de opções de diversificação.

\section{Fundamentação teórica}

As variáveis risco e incerteza têm sido largamente utilizadas dentro da teoria econômica, em que elas se distinguem com base no conhecimento sobre a probabilidade de ocorrer a renda ou o uso dos recursos. O risco é caracterizado por situações que ocorrem com probabilidade conhecida e a incerteza é caracterizada por situações onde a probabilidade de ocorrência do fenômeno não pode ser antecipada. O risco é tridimensional: o evento (ganho ou perda), a probabilidade de ocorrência (normalmente o evento indesejável) e o tempo (EHRLICH e MORAES, 2005).

No contexto empresarial o risco pode incidir em diversas áreas. Em termos gerais, sob a ótica econômica, a empresa espera obter retornos proporcionados pelas suas atividades, de acordo com sua função-utilidade. Tais atividades possuem seus resultados sujeitos a certos eventos e, por conta disso, geralmente existe um grau de incerteza sobre a efetivação destes resultados. $\mathrm{O}$ risco pode ser esse grau de incerteza quanto ao retorno esperado ou a probabilidade de ocorrência de perdas indesejadas (financeiras ou não). Mas, embora a administração de riscos seja uma atividade defendida por muitos administradores e economistas, nem todas as empresas se engajam efetivamente nesta prática. Frequentemente a gestão dos riscos está voltada principalmente a riscos de crédito e de mercado e, assim, o foco torna-se apenas a preocupação com as flutuações de preço e a análise de contratos de crédito (FRENKEL, HOMMEL e RUDOLF, 2000). As demais fontes de riscos nem sempre são levadas em consideração com maior profundidade.

No contexto das empresas do agronegócio, verifica-se que todas as empresas estão sujeitas a 
algum nível de risco. Nestas empresas, esses riscos são caracterizados por diversos fatores, entre eles as variabilidades e incertezas sobre preços e produção. Mas, normalmente, a eliminação destes riscos não é viável e nem desejável, uma vez que isso poderia também limitar a possibilidade de maiores rendimentos. O mais recomendável seria as empresas gerenciarem melhor as vantagens da relação retorno-risco e, com isso, não limitar a possibilidade de crescimento causada pela aversão ao risco (ZEULI, 1999).

Algumas fontes de riscos, como instabilidade climática e surgimento de pragas, por exemplo, são próprias do agronegócio. Outros tipos de riscos, como risco de mercado ou riscos institucionais, apesar de também estarem presentes no contexto empresarial, apresentam importâncias e características diferenciadas no contexto do agronegócio. Devido à variedade dos tipos e origens dos riscos no agronegócio e às particularidades inerentes a cada tipo de produtor rural, não há uma estratégia gerencial única comum a todos os produtores. Os produtores enfrentam tipos diferenciados de riscos e necessitam de ferramentas variadas para o seu gerenciamento (USDA, 2008).

Alguns estudos evidenciam que a percepção de produtores quanto à importância e à influência de cada tipo de risco em suas operações pode variar muito dependendo do tipo de empreendimento e da região em que se encontra. E as estratégias gerenciais adotadas para evitar e diminuir as consequências dos riscos também variam muito (PATRICK et al., 1985; HARDWOOD et al., 1999; GOMES, 2000; FLATEN et al., 2005; PINOCHETCHATEAU et al., 2005; HARDAKER et al., 2007; HEIDELBACH, 2007; USDA, 2008; MOREIRA, 2009). Frequentemente em estudos no campo da economia rural os tipos de riscos mais abordados são os riscos de mercado (FRENKEL, HOMMEL e RUDOLF, 2000). Isto se justifica em parte pela disponibilidade de métodos de modelagem e avaliação destes riscos, sobretudo os relacionados à teoria da utilidade que utilizam a programação matemática para o seu tratamento. No contexto brasileiro, além dos tipos, fontes e estratégias para gestão dos riscos mais conhecidas e estudadas em outros países, pode-secitar também a precariedade da infraestrutura logística (estradas, portos etc.) como uma fonte de riscos que influencia o custo total dos produtos. Além disso, a alta carga tributária, com impostos incidindo em cascata, e a manutenção de uma taxa de juros básica entre as mais altas do mundo, também contribuem para a incidência dos riscos de produção, de mercado, financeiros e institucionais.

No contexto cooperativo, verifica-se que as cooperativas agroindustriais, além de operarem em um ambiente que é intrinsecamente arriscado, também estão expostas a altos graus de riscos financeiros e de mercado. De acordo com Manfredo e Richards (2007), diversas situações geram esses tipos de riscos para as cooperativas. Normalmente as cooperativas focalizam suas atividades em poucas commodities e/ou operam em regiões geograficamente limitadas e/ou utilizam pequenos canais de vendas. A maioria das pequenas cooperativas, por exemplo, possui um baixo nível de diversificação e, normalmente, para as commodities que comercializam (como frutas, vegetais e hortifrutigranjeiros) não há opções de mercados futuros e nem de seguros disponíveis. Estas cooperativas não têm a oportunidade de gerir seus riscos usando as ferramentas do mercado. Muitas cooperativas também operam em arranjos do tipo pool (com compartilhamento das perdas), em que a produção dos seus membros deve ser vendida em determinado tempo pré-estipulado. Apesar de este tipo de arranjo ser interessante aos membros, que se liberam das preocupações com o "tempo de mercado", ele limita a possibilidade da cooperativa manter estoques e vendê-los quando o preço for mais atrativo. Tudo isso implica em altos níveis de riscos de mercado. Além disso, normalmente as cooperativas operam com pequenas margens de lucro, não possuem acesso a financiamentos via mercado financeiro (bolsa de valores) e têm necessidade de distribuição de resíduos (sobras) a seus membros. Estas características exigem que a cooperativa apresente altos graus de alavancagem e, por conseguinte, apresente também altos níveis de riscos financeiros. 
De acordo com Zeuli (1999), as estratégias para uma cooperativa agroindustrial diminuir os riscos na disponibilidade de oferta de matéria-prima para sua produção e na variabilidade da sua renda, seriam, respectivamente, a (i) expansão geográfica de seus membros e (ii) a diversificação da linha de produtos ofertada ao mercado. A primeira alternativa tem como vantagem a contribuição para a possibilidade de diversificação da produção da cooperativa por meio do aumento do número de fornecedores, mas implica maiores custos logísticos. A segunda tem como vantagem a diminuição dos riscos, mas implica maiores investimentos e custos de produção. Entretanto, um dos maiores obstáculos para a adoção destas medidas, buscando a melhor gestão dos riscos e a consequente eficiência econômica, é o possível conflito com os objetivos cooperativistas. Aumentar o número de associados (para garantir o suprimento da cooperativa e melhorar a diversificação) pode implicar em aumentar também os problemas relacionados à governança da cooperativa. Diversificar o portfólio de produção pode resultar na perda do foco estratégico da cooperativa e em conflito com a resistência geral dos membros por mudanças.

No contexto brasileiro, entre as características marcantes do cooperativismo, pode-se citar as áreas de atuação da cooperativa. Uma cooperativa agropecuária no Brasil pode ser ao mesmo tempo uma cooperativa de compra, de venda, de produção e de crédito. Frequentemente uma cooperativa pode executar atividades de venda de insumos aos membros, compra de produtos dos membros, venda de produtos ao mercado, industrialização (transformação) de commodities, venda de produtos com valor agregado ao mercado, associação com outras cooperativas para formar pool de compras, associação entre cooperativas para maximizar o uso de modais (como navios, por exemplo) etc. Dada a variedade de atividades que uma cooperativa pode desenvolver, os riscos que incidem em suas operações são de vários tipos e advêm de diversas fontes. Além disso, no
Brasil, as cooperativas ainda são consideradas organizações que possuem funções sociais e, apesar de ser um pré-requisito para o desempenho social, o desempenho econômico nem sempre é devidamente alcançado, aumentando, assim, a incidência de riscos financeiros.

Alguns autores têm se dedicado a estudar qual a capacidade das cooperativas em gerenciar os diversos riscos que incidem em suas operações e no ambiente em que estão inseridas (SHAPIRO e BRORSEN, 1988; ZEULI, 1999; BIALOSKORSKI NETO, 2001; FERREIRA, 2002; MANFREDO e RICHARDS, 2007; MOREIRA, 2009). Com relação ao risco de mercado, por exemplo, verifica-se que uma das estratégias mais aceitas para o seu gerenciamento é a diversificação da produção e/ou das atividades. Entretanto, no contexto cooperativista, verifica-se que essa estratégia não é facilmente aplicável. A cooperativa não possui a mesma flexibilidade da empresa mercantil para efetuar mudanças em seu portfólio (FERREIRA, 2002; MOREIRA, 2009).

\section{Metodologia}

Este estudo teve por objetivo principal desenvolver uma avaliação da gestão dos riscos de mercado do agronegócio e sua relação com o cooperativismo. Para tanto, foram executados os seguintes passos:

- Avaliação do portfólio de produção agropecuária do estado do Paraná;

- Avaliação dos riscos de mercado envolvidos na produção paranaense, por meio da construção de uma fronteira de eficiência;

- Definição de opções de portfólios eficientes considerando-se a relação risco-retorno e identificados por meio da fronteira de eficiência;

- Avaliação, por parte das cooperativas, da viabilidade das mudanças em preferências de produção, condizentes com as opções de portfólios eficientes;

- Avaliação das práticas das cooperativas na gestão dos riscos de mercado. 
Assim, após a análise da composição do portfólio de produção agropecuária do estado do Paraná, foi feita uma análise do histórico de produção e uma análise de séries históricas para avaliar a variabilidade das margens brutas de cada atividade (preço recebido pelo produtor subtraído dos custos estimados de produção). O período de tempo considerado foi de 1996 a 2006, sendo calculadas as margens brutas mensais para cada atividade. A variabilidade dessas margens foi utilizada como proxy para a medição dos riscos.

$\mathrm{Na}$ área de administração rural o termo margem bruta refere-se à subtração da renda bruta pelos custos variáveis. Além dessa medida de resultado econômico, é possível considerar a renda líquida, que é a subtração da margem bruta pelas depreciações, e o lucro, que é a subtração da renda líquida pelos juros sobre o capital fixo e a remuneração da terra. Essa classificação de medidas de resultado econômico é adotada pela Secretaria da Agricultura e Abastecimento do Paraná/Departamento de Economia Rural, (Seab/Deral), Conab (Companhia Nacional de Abastecimento) e Ocepar (Organização e Sindicato das Cooperativas do Estado do Paraná). Embora a margem bruta possa não refletir a totalidade do grau de desempenho financeiro dos produtores rurais, ela é adequada para fins de análise da variabilidade dos retornos brutos das commodities e, além disso, pode refletir de forma consistente as decisões de curto prazo do produtor rural sobre o quê produzir.

As séries históricas de preços pagos ao produtor foram obtidas junto à Seab/Deral. As séries históricas de estimativas de custos de produção foram obtidas junto ao Deral, à Conab e ao Agrianual (Anuário da Agricultura Brasileira) e Anualpec (Anuário da Pecuária Brasileira), ambos divulgados pela FNP Consultoria \& Agroinformativos. Os valores foram atualizados pela variação do Índice de Preços por Atacado Disponibilidade Interna (IPA-DI), que é divulgado pela Fundação Getulio Vargas (FGV). As séries históricas de produção foram obtidas junto ao Deral, ao Anualpec e à Embrapa (Empresa Brasileira de Pesquisa Agropecuária).
Para selecionar a combinação ótima de atividades produtivas que maximiza a margem bruta do agronegócio do Paraná, foi utilizada a programação linear. Na função-objetivo foram utilizadas, como coeficientes, as margens brutas médias do período de 1996 a 2006. Para as restrições foram utilizadas, considerando-se o período analisado, faixas de valores mínimos e máximos para a produção e área de cada atividade. Para as atividades relacionadas a lavouras (soja, milho, feijão, café, trigo, cana, fumo, mandioca, batata, tomate, laranja e uva), o cálculo da área necessária para a produção foi feito considerando-se a produtividade alcançada em 2006 (produção total dividida pela área colhida).

Todavia, apesar de muitos trabalhos utilizarem apenas a programação linear para resolver o problema da combinação ótima de atividades agropecuárias, este instrumental torna-se inadequado sem a consideração dos riscos. Isso porque ele tende a produzir soluções extremas (de canto) ou apenas soluções que envolvem altos graus de especialização, o que não se verifica na realidade do produtor rural. A análise dos riscos foi incorporada por meio da análise E-V (retorno-variância) de Markowitz (MARKOWITZ, 1952). Esta análise tem por objetivo minimizar a variância total de um portfólio. No contexto de modelagem de um portfólio de produção, o objetivo se torna a minimização da variância total das margens brutas históricas do conjunto de atividades considerado no estudo. Esta variância pode ser calculada por:

$$
V=\sum_{j} \sum_{k} X_{j} \sigma_{k} X_{k}
$$

em que $X_{j}$ é o nível da j-ésima atividade e $\sigma_{j k}$ é a covariância das margens brutas totais das $j$-ésimas e $k$-ésimas atividades (quando $j=k, \sigma_{j k}$ é a variância da margem bruta da atividade $j$ ). Segundo esta equação, que define a variância das margens brutas, verifica-se que a variância pode ser expressa pela variabilidade dos retornos individuais das atividades e a covariância entre eles.

Para a utilização do modelo E-V, inicialmente foi feita a análise de séries históricas para estimar a 
variabilidade da margem bruta das atividades (proxy para a medição dos riscos). A variabilidade das margens brutas foi calculada por meio da variância. O modelo foi resolvido com o auxílio de técnicas paramétricas, e isso possibilitou a geração da fronteira de eficiência econômica (retorno-risco). Abaixo são apresentados o modelo e os procedimentos usados para a geração da fronteira:

$$
\begin{aligned}
& \text { Minimizar } \quad V=\sum_{j}^{n} \sum_{k}^{n} X_{j} \sigma_{k} X_{k} \\
& \text { Sujeito a } \sum_{j=1}^{n} f_{j} X_{j}=\lambda \quad(\forall j=1, \ldots, n) \text { e demais }
\end{aligned}
$$

restrições do modelo linear.

Em que $f_{j}$ é a margem bruta esperada da j-ésima atividade e $\lambda$ é o coeficiente de parametrização. A função-objetivo do modelo é quadrática quando $j=k$ e, por conta disso, deve ser revolvida por um algoritmo de programação quadrática. O somatório da primeira restrição representa a acumulação da multiplicação entre as margens brutas esperadas $\left(f_{j}\right)$ e os níveis das atividades correspondentes $\left(X_{\mathrm{j}}\right)$, determinando, assim, a margem bruta total esperada $E$. Esta soma deve ser igualada ao parâmetro $\lambda$. Parametrizando $\lambda$ do valor mínimo possível para $E$ (margem bruta total) até o valor máximo encontrado no modelo de programação linear, é encontrada uma sequência de soluções relacionando margens brutas totais e variâncias totais, considerando-se as restrições impostas ao modelo. O valor mínimo para $E$ foi calculado segundo as restrições de produção mínima para cada atividade (menor nível de produção de cada atividade no período analisado). Para cada valor de $\lambda$ tem-se um valor de margem bruta total $E$ tal que a variância total $V$ é mínima. Este conjunto de pares define a fronteira de eficiência, onde a ordenada equivale às margens brutas totais e a abscissa, às variâncias relacionadas (proxy para o risco) (HAZELL e NORTON, 1986).

Depois de construída a fronteira de eficiência, foi possível verificar em qual posição a produção de 2006 se encontra em termos de retorno-risco. Essa verificação se deu por meio da avaliação da posição relativa da produção de 2006 (níveis de produção verificados nesse ano) em relação à fronteira de eficiência. Também foram analisados os níveis de produção de 2005, 2004, 2003 e 2002 e posicionados os pontos no espaço retorno- -risco, permitindo, assim, uma comparação com o desempenho de 2006. Com a análise retorno-risco foi possível avaliar quais seriam as alterações necessárias no portfólio de produção de commodities agropecuárias do estado do Paraná visando a máxima eficiência econômica. Tais alterações teriam como consequência uma mudança nas preferências de produção e, consequentemente, afetaria a operação das cooperativas agropecuárias do estado. Para avaliar qual seria a disposição das cooperativas para incentivar as alterações propostas junto aos seus cooperados e quais seriam os motivos para a não adesão às propostas, foi enviado um questionário e foram feitas entrevistas semiestruturadas com os gestores das cooperativas.

O questionário foi enviado às 65 cooperativas agropecuárias que constam do cadastro da Ocepar. Houve retorno de 14 questionários, representando uma amostra de 21,5\%. Conforme os dados da Organização (OCEPAR, 2008), em termos de faturamento, a amostra representa aproximadamente $52 \%$ do faturamento das cooperativas do estadoe, em termos de cooperados, a quantidade de associados ativos representa em torno de $33 \%$ do total de cooperados do estado. Das cooperativas da amostra verifica-se uma alta absorção da produção dos cooperados, com a maioria recebendo mais de $70 \%$ da produção. No questionário foi solicitado o preenchimento por um gestor, diretor, superintendente ou pelo presidente da cooperativa. Entre os respondentes houve uma participação significativa da alta administração, representada pelos diretores presidentes, diretor executivo, diretor superintendente, gerentes e pelos presidentes.

No questionário foi apresentada uma lista de motivos que poderiam influenciar na decisão da cooperativa em não investir ou incentivar a produção dos itens analisados no modelo de eficiência econômica gerado. O objetivo foi avaliar, entre algumas características particulares da doutrina cooperativista, se as cooperativas estariam dispostas a incentivar mudanças no portfólio de produção agropecuária de seus membros e quais seriam os motivos que poderiam 
influenciar nessa decisão. Para o preenchimento destas questões foi solicitado que o respondente desconsiderasse os itens em que a cooperativa atualmente se dispõe a incentivar o aumento ou a manutenção da produção atual. Também foi solicitado que fossem consideradas as hipóteses de viabilidade técnica e econômica, a capacidade de absorção da cooperativa e a possibilidade de expansão geográfica para os casos em que não há vocação regional para a cultura. Essas hipóteses foram colocadas para tentar isolar os motivos para não investir ou incentivar a produção, direcionando-os apenas aos motivos listados. Para cada motivo foi perguntado qual o grau de influência - pouca ou muita. Os motivos e os objetivos de sua investigação são apresentados na seção de discussão dos resultados. Por fim, foi feita uma análise sobre a percepção de gestores de quatro cooperativas sobre os resultados apresentados na análise referente ao escopo de produção proposto pelos dois cenários gerados pelo modelo, com o objetivo de verificar a aderência entre a teoria e a prática dos negócios.

\section{Região do estudo e variáveis do modelo $\mathrm{E}-\mathrm{V}$}

A avaliação inicial do portfólio de produção agropecuária do Paraná foi feita com base na análise do relatório anual do Deral, da Seab, denominado de Valor Bruto da Produção Agropecuária Paranaense. Este órgão acompanha sistematicamente a evolução da produção do agronegócio desse estado e sintetiza as informações neste relatório. Na Tabela 1 é apresentado o Valor Bruto da Produção (VBP) agropecuária do Paraná no ano-base 2005/2006 e a variação na participação de cada grupo nos últimos 10 anos. Nesta tabela o grupo "Principais Culturas" inclui, entre outros, os principais grãos como soja, milho, café, feijão e trigo e também cana-de-açúcar, fumo e mandioca. O grupo "Pecuária" inclui, entre outros, aves, bovinos, suínos e produção de leite e ovos. O grupo "Produtos Florestais" inclui a produção de madeiras em tora. O grupo "Hortaliças e Especiarias" inclui, entre outros, batata, couve-flor e tomate. O grupo "Fruticultura" inclui, entre outros, laranja e uva. Percebe-se que a produção tem se reconfigurado nos últimos anos. Isso pode ser reflexo de uma alteração das preferências e/ ou possibilidades de produção dos proprietários rurais do estado.

Embora a produção agropecuária do estado seja consideravelmente diversificada (509 itens compõem o VBP do estado), 70,05\% do VBP é formado por apenas 17 itens. Estes produtos, por serem os mais representativos da produção agropecuária paranaense, foram utilizados como variáveis no modelo. No Quadro 1 são apresentados os produtos que foram utilizados como variáveis e a representatividade de cada um no VBP de 2005/2006. Cada grupo e subgrupo de culturas do agronegócio, desenvolvidas no estado, ficaram representados por estes itens,

Tabela 1. Comparativo do valor bruto da produção (VBP) do Paraná.

\begin{tabular}{|c|c|c|c|c|c|}
\hline \multirow{2}{*}{ Grupos } & \multicolumn{2}{|c|}{ VBP 96/97 } & \multicolumn{2}{|c|}{ VBP 05/06 } & \multirow{2}{*}{$\begin{array}{c}\Delta \% \\
\mathrm{~b} / \mathrm{a}\end{array}$} \\
\hline & Valor (R\$ mil) (a) & $\%$ PR & Valor (R\$ mil) (b) & $\%$ PR & \\
\hline Principais culturas & 9.982 .651 & 48,22 & 10.764 .126 & 41,76 & 7,83 \\
\hline Pecuária & 7.828 .407 & 37,81 & 9.940 .522 & 38,56 & 26,98 \\
\hline Produtos florestais & 1.422 .717 & 6,87 & 3.079 .651 & 11,95 & 116,46 \\
\hline Hortaliças e especiarias & 922.092 & 4,45 & 1.285 .895 & 4,99 & 39,45 \\
\hline Fruticultura & 536.402 & 2,59 & 663.541 & 2,57 & 23,70 \\
\hline Floricultura & 10.708 & 0,05 & 45.405 & 0,18 & 324,04 \\
\hline Total do Paraná & 20.702 .977 & 100,00 & 25.779 .140 & 100,00 & 24,52 \\
\hline
\end{tabular}

Fonte: Andretta (2008). 
Quadro 1. Variáveis consideradas no modelo de análise E-V (retorno-variância) de Markowitz.

\begin{tabular}{|c|c|c|c|}
\hline Grupos/Produtos & $\%$ do VBP & Grupos/Produtos & $\%$ do VBP \\
\hline PRINCIPAIS CULTURAS & 41,76 & PECUÁRIA & 38,56 \\
\hline Grãos de Verão e Algodão & & Aves & \\
\hline Soja & 15,193 & Frangos & 11,031 \\
\hline Milho & 9,676 & Outras aves & 3,894 \\
\hline Feijão & 3,110 & Bovinos & \\
\hline Café & 1,863 & Bois/Vacas & 5,079 \\
\hline Outros & 0,424 & Outros bovinos & 3,513 \\
\hline Grãos de Inverno & & Suinos & \\
\hline Trigo & 2,101 & Suíno de raça & 3,614 \\
\hline Outros & 0,542 & Outros suínos & 1,143 \\
\hline Outras Culturas de Verão & & Pecuária comercial & \\
\hline Cana-de-açúcar & 4,883 & Leite & 4,961 \\
\hline Fumo & 2,282 & Ovos de Galinha & 1,673 \\
\hline Mandioca & 1,536 & Outros & 0,347 \\
\hline Demais produtos & 0,023 & Silagens e Capineiras & 1,47 \\
\hline Sementes de Grãos e Outros & 0,126 & Outros Grupos & 1,84 \\
\hline PRODUTOS FLORESTAIS & 11,95 & FRUTICULTURA & 2.57 \\
\hline HORTALIÇAS E ESPECIARIAS & 4,99 & Laranja & 0,663 \\
\hline Batata Inglesa & 1,693 & Uva & 0,602 \\
\hline Tomate & 0,516 & Outros & 1,305 \\
\hline Outras & 2,23 & FLORICULTURA & 0,18 \\
\hline
\end{tabular}

Nota: 1) Itens em negrito representam as culturas escolhidas de cada grupo de produção para a aplicação no modelo. A escolha ocorreu pela maior representatividade relativa da cultura em cada grupo; 2) VBP = Valor Bruto da Produção.

Fonte: Elaboração própria e Andretta (2008).

com exceção do grupo de produtos florestais (por não haver dados históricos de preços e custos) e do grupo floricultura (por ter uma representatividade muito baixa com relação ao valor bruto da produção). Os itens feijão e fumo foram considerados, respectivamente, de forma separada como feijão preto e de cor e fumo galpão e fumo estufa, devido às cotações diferenciadas de preços pagos ao produtor. Por este motivo, o modelo teve, no total, 19 variáveis.

\section{Análise do portfólio de produção de commodities do agronegócio do Paraná}

No contexto do agronegócio frequentemente verifica-se uma migração importante para culturas com maior rentabilidade quando da ocorrência de crises em outras culturas. Entretanto, os preços dos produtos agrícolas refletem o equilíbrio entre oferta e demanda e, normalmente, um produto que está apresentando boa rentabilidade em um determinado momento pode estar subofertado em relação à sua demanda potencial. Assim, o aumento da oferta ocasionado pela migração da produção pode derrubar os preços e prejudicar os produtores recém-chegados na cultura. Neste caso, uma das consequências da variação dos níveis de produção é a variabilidade das margens brutas, uma vez que a variação na oferta influencia diretamente nos preços pagos ao produtor. $\mathrm{Na}$ agricultura os mercados se caracterizam pela concorrência quase perfeita e as variações de oferta e em alguns casos de demanda determinadas por fatores sazonais ou estacionais, são de grande importância nas mudanças de comportamento dos preços agrícolas (AGRIANUAL, 1998).

No período de 1996 a 2006 verificou-se uma grande variação do nível de produção agropecuária no estado do Paraná para os 19 itens analisados no estudo. A Tabela 2 apresenta os níveis de produção dos itens no período. Para o item suíno, a série histórica de produção estava disponível apenas para o período de 2002 
Tabela 2. Níveis históricos da produção agropecuária do Paraná em unidades produtivas - 1996 a 2006.

\begin{tabular}{lcccccccccccc}
\hline \multicolumn{1}{c}{ Itens } & u.m. & $\mathbf{1 9 9 6}$ & $\mathbf{1 9 9 7}$ & $\mathbf{1 9 9 8}$ & $\mathbf{1 9 9 9}$ & $\mathbf{2 0 0 0}$ & $\mathbf{2 0 0 1}$ & $\mathbf{2 0 0 2}$ & $\mathbf{2 0 0 3}$ & $\mathbf{2 0 0 4}$ & $\mathbf{2 0 0 5}$ & $\mathbf{2 0 0 6}$ \\
\hline Soja & ton & 6440 & 6582 & 7313 & 7752 & 7200 & 8628 & 9566 & 11019 & 10220 & 9553 & 3949 \\
Milho & ton & 7934 & 7752 & 7935 & 8777 & 7367 & 12690 & 9858 & 14403 & 10935 & 8548 & 11697 \\
Feijão preto & ton & 243 & 232 & 230 & 263 & 242 & 216 & 293 & 324 & 308 & 256 & 344 \\
Feijão cor & ton & 247 & 244 & 264 & 307 & 259 & 255 & 336 & 394 & 358 & 299 & 475 \\
Café & ton & 77 & 110 & 136 & 142 & 132 & 28 & 139 & 117 & 148 & 86 & 139 \\
Trigo & ton & 1986 & 1629 & 1509 & 1447 & 599 & 1840 & 1558 & 3122 & 3051 & 2804 & 1205 \\
Cana & ton & 23440 & 24564 & 26641 & 27017 & 23190 & 27156 & 28121 & 32721 & 32550 & 28342 & 34462 \\
Fumo estufa & ton & 42 & 52 & 40 & 48 & 45 & 48 & 58 & 71 & 90 & 107 & 109 \\
Fumo galpão & ton & 18 & 22 & 17 & 20 & 19 & 21 & 25 & 30 & 38 & 46 & 47 \\
Mandioca & ton & 2584 & 2941 & 3242 & 3447 & 3780 & 3615 & 3464 & 2476 & 2969 & 3347 & 3789 \\
Frangos & ton & 708 & 740 & 867 & 1011 & 1136 & 1344 & 1564 & 1694 & 1907 & 2097 & 2081 \\
Bois/Vacas & ton & 554 & 514 & 522 & 517 & 518 & 564 & 505 & 503 & 519 & 549 & 557 \\
Suíno & ton & & & & & & & 432 & 409 & 372 & 390 & 403 \\
Leite & mil l & 1514 & 1580 & 1625 & 1725 & 1799 & 1890 & 1985 & 2141 & 2395 & 2519 & 2665 \\
Ovos & dúzia & 2997 & 2280 & 2375 & 2572 & 2576 & 2662 & 2870 & 3692 & 3838 & 3370 & 3280 \\
Batata Lisa & ton & 726 & 662 & 589 & 616 & 648 & 594 & 659 & 609 & 580 & 530 & 585 \\
Tomate & ton & 100 & 90 & 102 & 105 & 118 & 138 & 159 & 164 & 161 & 186 & 204 \\
Uva & ton & 32 & 31 & 61 & 64 & 69 & 80 & 75 & 75 & 97 & 75 & 68 \\
Laranja pêra & ton & 149 & 216 & 275 & 345 & 365 & 302 & 396 & 332 & 398 & 365 & 412 \\
\hline
\end{tabular}

Nota: Valores em milhares.

Fonte: Anualpec, Deral, Embrapa.

a 2006 e foi obtida junto à Embrapa. As séries históricas dos itens frango, boi, leite e ovos foram obtidas junto ao Anualpec. As séries históricas de produção e área plantada dos demais itens foram obtidas junto ao Deral.

Verifica-se que para alguns itens a variabilidade dos níveis de produção foi bem acentuada, com destaque para soja (que teve produção ascendente até o ano de 2003), milho (com quebras de produção em 2002 e 2005), café (quebras em 2001 e 2005), trigo (decrescimento da produção entre 1996 e 2000; e crescimento e decrescimento até 2006). O resultado de margens esperadas negativas para os itens milho, trigo, leite e ovos, calculadas e usadas no modelo de maximização, pode ser reflexo da alta variação dos níveis de produção, para o caso do milho, e da constante alta dos níveis de produção que aumentaram a oferta, para trigo, leite e ovos. No caso do trigo em especial, verifica-se que, apesar de o Brasil não ser autossuficiente nesta cultura, uma oferta excessiva na produção normalmente ocasiona problemas de comercialização, uma vez que a produção do trigo na região Sul não é exportada para o restante do País devido ao alto custo logístico.

Os motivos para a variabilidade nos níveis de produção são diversos, entre eles podem-se citar a variação climática, incluindo falta ou excesso de chuvas, a variação dos níveis tecnológicos, a disponibilidade de crédito e o nível de endividamento dos produtores, a variação na demanda e nos preços, entre outros. A maximização do modelo de programação linear usado no estudo também apresenta variações significativas nos níveis de produção de alguns itens, com relação aos níveis de produção alcançados em 2006. Verifica-se um potencial de crescimento da margem bruta total em torno de $36 \%$ como consequência do ajuste dos níveis de produção de alguns dos itens.

No modelo otimizado (apresentado abaixo na Figura 1, na coluna "Máx. PL"), considerando-se os níveis de produção de 2006, os itens com margem esperada favorável (positiva) tiveram a produção aumentada ou estável, tendo como 
Figura 1. Fronteira de eficiência do agronegócio paranaense - 2002 a 2006.

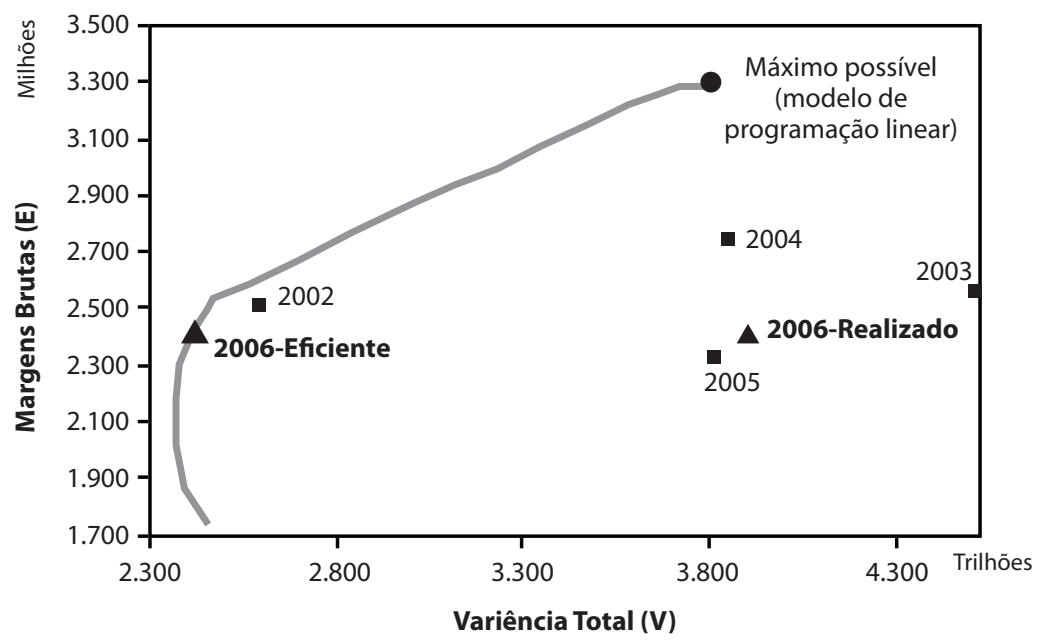

Fonte: Elaboração própria.

limitante a área máxima histórica (para os itens de lavoura) ou a produção máxima histórica. Os itens com margem esperada desfavorável (negativa) tiveram a produção diminuída até o parâmetro de área mínima histórica ou produção mínima histórica. A margem esperada foi calculada pela média das margens brutas históricas do período de 1996 a 2006. Os itens milho, trigo, leite e ovos apresentaram margem esperada.

A incorporação do risco na análise do portfólio de produção se deu por meio da matriz de covariância das margens brutas mensais dos itens durante o período de análise (1996-2006), definindo a análise E-V (retorno-risco). Com a incorporação dos riscos foi possível traçar a fronteira de eficiência, relacionando retorno e risco e definindo os portfólios eficientes. A Figura 1 apresenta a fronteira de eficiência gerada e os pontos correspondentes às produções de 2002 a 2006, o ponto da máxima eficiência para 2006 e o ponto com a produção máxima possível, determinada pelo modelo linear.

Com base no histórico de produção, foram posicionados no espaço retorno-risco os pontos referentes aos portfólios de produção de 2002 a 2006, considerando-se a margem bruta total alcançada (E) e a variância total (V) dos portfólios em cada ano. Assim, foi possível comparar o posicionamento da produção de cada ano e as possíveis variações viáveis visando à máxima eficiência (em termos de riscos de mercado medidos pela relação retorno-risco). Verifica-se que, para 2006, seria possível reduzir consideravelmente o risco (variância total) mantendo-se o mesmo nível de rentabilidade. Além disso, para um nível de risco semelhante, seria possível aumentar a rentabilidade também de forma significativa. Com exceção de 2002 e 2003, os demais anos apresentam níveis próximos de risco, sendo que, em 2004, houve a maior margem bruta total. O ano de 2002, quando comparado à fronteira de eficiência da situação de 2006, foi o que apresentou a melhor relação retorno-risco. Ou seja, foi o ano em que o portfólio de produção foi o mais eficiente economicamente em termos de gestão de riscos (comparando-se com a situação de 2006).

AVBP 05/06Tabela 3 apresenta, com os valores expressos em milhares, o portfólio de produção de cada ano analisado na fronteira e as possíveis variações do portfólio de 2006 visando eficiência econômica. Com exceção de leite e ovos, cujas unidades de medida são, respectivamente, mil litros e dúzias, os demais itens utilizam toneladas como unidade de medida. 
Tabela 3. Cenários de portfólios eficientes e análise da evolução da produção.

\begin{tabular}{|c|c|c|c|c|c|c|c|c|c|}
\hline & $2006 R$ & $2006 \mathrm{E}$ & Var. & Máx. PL & Var. & 2005 & 2004 & 2003 & 2002 \\
\hline Margem (E) & 2422518 & 2422518 & $0,0 \%$ & 3301308 & $36,3 \%$ & 2334639 & 2746372 & 2568170 & 2508924 \\
\hline Variância (V) & 3895,0 & 2422,1 & $-37,8 \%$ & 3807,1 & $-2,3 \%$ & 3802,8 & 3851,1 & 4504,2 & 2592,7 \\
\hline Soja & 9466,4 & 5593,6 & $-40,9 \%$ & 10041,6 & $6,1 \%$ & 9552,7 & 10219,9 & 11018,7 & 9565,9 \\
\hline Milho & 11697,4 & 8745,0 & $-25,2 \%$ & 8745,0 & $-25,2 \%$ & 8548,4 & 10934,6 & 14403,5 & 9857,5 \\
\hline Feijão preto & 344,3 & 265,6 & $-22,9 \%$ & 420,1 & $22,0 \%$ & 255,5 & 307,9 & 323,7 & 293,2 \\
\hline Feijão de cor & 474,7 & 321,7 & $-32,2 \%$ & 524,1 & $10,4 \%$ & 299,1 & 358,2 & 394,3 & 335,9 \\
\hline Café & 139,4 & 196,2 & $40,7 \%$ & 196,2 & $40,7 \%$ & 86,4 & 148,3 & 117,3 & 139,1 \\
\hline Trigo & 1204,7 & 691,8 & $-42,6 \%$ & 691,8 & $-42,6 \%$ & 2804,2 & 3051,2 & 3121,5 & 1557,5 \\
\hline Cana & 34461,6 & 34461,6 & $0,0 \%$ & 34461,6 & $0,0 \%$ & 28342,4 & 32550,2 & 32721,4 & 28120,7 \\
\hline Fumo estufa & 108,9 & 44,2 & $-59,4 \%$ & 108,9 & $0,0 \%$ & 107,2 & 89,7 & 70,5 & 57,6 \\
\hline Fumo galpão & 46,7 & 46,7 & $0,0 \%$ & 46,7 & $0,0 \%$ & 45,9 & 38,4 & 30,2 & 24,7 \\
\hline Mandioca & 3789,2 & 2413,6 & $-36,3 \%$ & 4082,7 & $7,7 \%$ & 3347,4 & 2968,8 & 2476,3 & 3464,0 \\
\hline Frangos & 2081,1 & 2097,1 & $0,8 \%$ & 2097,1 & $0,8 \%$ & 2097,1 & 1907,0 & 1694,0 & 1563,9 \\
\hline Bovinos & 557,1 & 564,4 & $1,3 \%$ & 564,4 & $1,3 \%$ & 548,6 & 518,7 & 503,0 & 505,1 \\
\hline Suíno & 403,2 & 432,0 & $7,2 \%$ & 432,0 & $7,2 \%$ & 389,6 & 371,6 & 408,8 & 432,0 \\
\hline Leite & 2665,4 & 1514,5 & $-43,2 \%$ & 1514,5 & $-43,2 \%$ & 2518,9 & 2394,5 & 2141,5 & 1985,3 \\
\hline Ovos & 3279,8 & 2279,7 & $-30,5 \%$ & 2279,7 & $-30,5 \%$ & 3370,1 & 3837,7 & 3692,5 & 2870,3 \\
\hline Batata & 585,3 & 637,1 & $8,9 \%$ & 1010,3 & $72,6 \%$ & 530,0 & 580,4 & 609,0 & 659,4 \\
\hline Tomate & 204,1 & 204,1 & $0,0 \%$ & 204,1 & $0,0 \%$ & 186,3 & 161,4 & 164,3 & 159,5 \\
\hline Uva & 67,8 & 101,5 & $49,7 \%$ & 101,5 & $49,7 \%$ & 74,9 & 96,7 & 74,9 & 75,1 \\
\hline Laranja & 411,7 & 411,7 & $0,0 \%$ & 411,7 & $0,0 \%$ & 365,2 & 397,9 & 332,3 & 396,3 \\
\hline
\end{tabular}

Nota: Valores em milhares; $2006 \mathrm{R}$ = Produção Realizada; 2006 E = Produção Eficiente.

Comparando-se a situação de 2006, a produção real (coluna $2006 \mathrm{R}$ ) poderia ter uma redução de $37,8 \%$ da variância total (risco) com a mesma margem bruta total se o portfólio de produção fosse o indicado pela produção eficiente (coluna 2006 E). Com relação à produção máxima indicada pelo modelo de programação linear (coluna Máx. PL), para um nível de risco praticamente estável $(-2,3 \%)$, seria possível aumentar a margem bruta total de $2006 \mathrm{em}$ torno de $36 \%$. Os percentuais de variação que indicam quais seriam as mudanças no portfólio realizado de 2006 (2006 R) visando o portfólio eficiente (2006 E), apontam para a diminuição na produção das culturas que possuem maior variabilidade nas margens brutas e/ou apresentam baixa ou negativa margem esperada, considerando-se o período de 1996 a 2006. Os anos de 2004, 2005 e 2006 apresentaram um nível de risco (V) semelhante, com 2004 apresentando maior margem bruta total. Para verificar quais seriam as mudanças necessárias nos portfólios de 2002 a
2005, com o objetivo de obter máxima eficiência em termos de retorno-risco, seria necessário traçar a fronteira de eficiência individual para cada um dos anos.

Para os itens mais representativos do VBP do estado (soja, frango e milho), as cooperativas apresentam graus alto, baixo e médio, respectivamente, de absorção da produção. Verifica-se que a maioria dos itens que deveriam sofrer as variações nos níveis de produção com vistas à melhoria na relação retorno-risco são representativos na atividade cooperativa do estado. Para o cenário de diminuição do risco (redução de 37,8\% na variância total do portfólio) com a manutenção da margem bruta total, por meio de mudanças dos níveis de produção indicados em "2006 R" para os níveis indicados em "2006 E", verifica-se que, entre os itens que deveriam ter sua produção diminuída, as cooperativas absorvem a produção de soja, milho, feijão, trigo, mandioca e leite. Entre os itens que deveriam ter sua produção aumentada, 
as cooperativas absorvem a produção de café, suínos e batata. Entre os itens em que não há histórico de absorção da produção e que poderiam impactar na melhoria retorno-risco, destaca-se o item uva. Corroborando com este resultado, na opinião de técnicos da Ocepar, a fruticultura é uma atividade que deveria ser incentivada dada sua potencialidade em níveis de renda e baixa volatilidade. Para o cenário de aumento da margem bruta total $(+36,3 \%)$ com a manutenção do risco (diminuição de apenas 2,3\% na variância total do portfólio), por meio de mudanças dos níveis de produção indicados em "2006 R" para os níveis indicados em "Máx. PL", verifica-se que, entre os itens que deveriam ter sua produção diminuída, as cooperativas absorvem a produção de milho, trigo e leite. Entre os itens que deveriam ter sua produção aumentada, as cooperativas não absorvem a produção somente de bovinos e uva.

É possível verificar que, para ambos os cenários avaliados, a variação nos níveis de produção (para mais ou para menos) teria algum impacto na atividade cooperativa. Neste caso, as alterações no portfólio de absorção das cooperativas poderiam impactar na relação retorno-risco da produção agropecuária do estado do Paraná e, considerando-se que as cooperativas poderiam incentivar tais alterações, consequentemente, as cooperativas teriam condições de auxiliar na gestão dos riscos de mercado do agronegócio deste estado.

Entretanto, cabe ressaltar que os resultados relacionando as variações necessárias para partir do portfólio realizado em 2006 em direção aos portfólios eficientes, levam em consideração somente a visão econômica e racional que embasa o modelo de Markowitz (análise E-V). Sob outras perspectivas, tais como a social ou a de estratégia de mercado, por exemplo, tais variações poderiam ser inviáveis. No contexto das cooperativas a racionalidade econômica poderia conflitar com a racionalidade política e social, fortemente presente na doutrina cooperativa. Além disso, grandes alterações nas preferências de produção dos itens considerados na análise poderiam implicar em grandes investimentos na estrutura produtiva das cooperativas. Todavia, qualquer movimento rumo à diminuição da variabilidade da renda total do agronegócio influencia diretamente na segurança do produtor rural, sobretudo os de pequeno porte, que são maioria no Brasil, e isso seria desejável para todos os envolvidos no contexto do agronegócio.

\section{Influência das cooperativas na gestão dos riscos de mercado do agronegócio}

Conforme comentado na seção de metodologia, para avaliar se as cooperativas estariam dispostas a incentivar as alterações propostas no modelo, visando à melhoria da relação retorno-risco, inicialmente foi enviado um questionário às cooperativas agropecuárias do Paraná. No questionário foram apresentados alguns motivos que poderiam influenciar as decisões das cooperativas referentes a mudanças nos seus portfólios e foi perguntado qual o grau de influência de cada motivo. Os motivos investigados nos questionários e os objetivos de sua investigação são apresentados no 10.764.1262.

A Tabela 4 reproduz de forma resumida os cenários de eficiência econômica, gerados por meio da análise E-V e apresentados na Tabela 3, com os itens que deveriam ter seu nível de produção aumentado por conta dos objetivos ilustrados nos cenários. A tabela também inclui a lista dos motivos que exerceriam muita influência na decisão em não investir ou incentivar a produção destes itens. Para diminuir a variância total do portfólio de produção agropecuária do estado do Paraná, mantendo-se o mesmo nível de margem bruta total (cenário 2006 E), seria necessário aumentar a produção de café, frangos, bovinos, suínos, batata e uva; além de diminuir ou manter o nível de produção dos demais itens. Para maximizar a margem bruta total, mantendo-se quase o mesmo nível de risco (cenário Máx. PL), seria necessário aumentar a produção de soja, feijão, café, mandioca, frangos, bovinos, suínos, batata e uva; além de diminuir ou manter o nível de produção dos demais itens. 
Quadro 2. Motivos para não investir ou incentivar a produção dos itens do agronegócio considerados no modelo de análise retorno-risco.

\begin{tabular}{|l|l|}
\hline \multicolumn{1}{|c|}{ Motivos } & \multicolumn{1}{c|}{ Objetivo } \\
\hline $\begin{array}{l}\text { 1. Desequilíbrio entre os objetivos } \\
\text { econômico e social da cooperativa }\end{array}$ & $\begin{array}{l}\text { Investigar se a doutrina cooperativa, refletida nos objetivos sociais, que enfatizam as dife- } \\
\text { renças entre as cooperativas e outras organizações mercantis, poderia exercer algum grau } \\
\text { de influência nas decisões que causariam impacto no grau de diversificação da cooperativa } \\
\text { e dos cooperados. }\end{array}$ \\
\hline $\begin{array}{l}\text { 2. As opções são contrárias aos prin- } \\
\text { cípios da cooperativa }\end{array}$ & $\begin{array}{l}\text { Investigar se ainda haveria algum indício da influência da doutrina cooperativa nas deci- } \\
\text { sões sobre investimentos ou incentivos à diversificação. }\end{array}$ \\
\hline $\begin{array}{l}\text { 3. Não promoveria o bem-estar co- } \\
\text { mum }\end{array}$ & $\begin{array}{l}\text { Avaliar quais itens não seriam opções desejáveis na tentativa de diversificação. Estes itens } \\
\text { representariam as atividades em que as cooperativas poderiam ter mais resistência em in- } \\
\text { vestir ou incentivar a produção. }\end{array}$ \\
\hline $\begin{array}{l}\text { 4. Não promoveria progresso eco- } \\
\text { nômico aos cooperados }\end{array}$ & $\begin{array}{l}\text { Avaliar quais os itens do agronegócio que sofreriam mais resistência por parte das coopera- } \\
\text { tivas na intenção de diversificar o portfólio de produção dos cooperados. }\end{array}$ \\
\hline $\begin{array}{l}\text { 5. Incompatibilidade com o foco es- } \\
\text { tratégico da cooperativa }\end{array}$ & $\begin{array}{l}\text { Verificar diferenças entre os focos estratégicos das cooperativas com relação à disposição à } \\
\text { diversificação. }\end{array}$ \\
\hline $\begin{array}{l}\text { 6. Incompatibilidade com o históri- } \\
\text { co de produção da cooperativa }\end{array}$ & $\begin{array}{l}\text { Avaliar a influência que a experiência de decisões de produção do passado poderia exercer } \\
\text { nas decisões atuais. }\end{array}$ \\
\hline $\begin{array}{l}\text { 7. Possíveis resistências a mudanças } \\
\text { por parte dos cooperados }\end{array}$ & $\begin{array}{l}\text { Avaliar a possibilidade de haver resistências significativas a mudanças por parte dos coope- } \\
\text { rados em relação a propostas de diversificação com a consequente alteração nas preferên- } \\
\text { cias de produção. }\end{array}$ \\
\hline
\end{tabular}

Tabela 4. Cenários e motivos com muita influência.

\begin{tabular}{lcccc}
\hline \multicolumn{1}{c}{ Itens } & Variação para 2006 E & Motivos & Variação para Máx. PL & Motivos \\
\hline Soja & $-40,9 \%$ & & $6,1 \%$ & $3,4,5,6,7$ \\
Feijão preto & $-22,9 \%$ & & $22,0 \%$ & $3,4,5,6,7$ \\
Feijão de cor & $-32,2 \%$ & & $10,4 \%$ & 5,6 \\
Café & $40,7 \%$ & 5,6 & $70,7 \%$ & $1,2,5,6,7$ \\
Mandioca & $-36,3 \%$ & & $0,7 \%$ & $5,6,7$ \\
Frangos & $0,8 \%$ & $5,6,7$ & $1,3 \%$ & $5,6,7$ \\
Bovinos & $1,3 \%$ & $5,6,7$ & $7,2 \%$ & $2,4,5,6,7$ \\
Suíno & $7,2 \%$ & $2,4,5,6,7$ & $72,6 \%$ & $1,2,3,5,6,7$ \\
Batata & $8,9 \%$ & $1,2,3,5,6,7$ & $49,7 \%$ & $1,2,5,6,7$ \\
Uva & $49,7 \%$ & $1,2,5,6,7$ & & \\
\hline
\end{tabular}

Legenda: Motivo 1 - Desequilíbrio entre os objetivos econômicos e social da cooperativa; Motivo 2 - As opções são contrárias aos princípios da cooperativa; Motivo 3 - Não promoveria o bem-estar comum; Motivo 4 - Não promoveria o progresso econômico aos cooperados; Motivo 5 Incompatibilidade com o histórico da produção da cooperativa; Motivo 6 - Incompatibilidade com o histórico de produção da cooperativa; Motivo 7 - Possíveis resistências a mudanças por parte dos cooperados.

O item soja é o que sofreria menor influência dos motivos listados na decisão em não investir ou incentivar a sua produção. Os motivos comuns a todos os itens (exceção soja) em ambos os cenários foram os motivos 5 e 6 . Ou seja, a incompatibilidade com o foco estratégico e com o histórico de produção da cooperativa seria o que mais influenciaria na decisão em não investir ou incentivar a produção.

No cenário de diminuição da variância total para o mesmo nível de margem bruta total (cenário 2006 E), além dos motivos 5 e 6, os motivos 2 e 7 também foram os mais citados. Ou seja, o desequilíbrio entre os objetivos econômicos e sociais da cooperativa e possíveis resistências a mudanças por parte dos cooperados seriam os motivos com muita influência em não investir ou incentivar a produção de bovinos, suínos, batata e uva. Neste cenário, para os itens café e uva, que deveriam registrar as maiores alterações no nível de produção, os motivos comuns para não investir ou incentivar a produção são os relacionados à 
incompatibilidade com o foco estratégico (motivo 5) e com o histórico de produção da cooperativa (motivo 6).

No cenário de maximização da margem bruta total com pequena alteração da variância total do portfólio (cenário Máx. PL), os itens que deveriam ter as maiores alterações em seu nível de produção são feijão, café, batata e uva. Os motivos relacionados às características distintivas das cooperativas (motivos 1 e 2) influenciariam na decisão em não investir ou incentivar a produção de mandioca, suíno, batata e uva. O destaque na análise desse cenário é a indicação do motivo 7 para quase todos os itens. Ou seja, para quase todos os itens que melhorariam a relação retorno-risco, maximizando a margem bruta total para o mesmo nível de risco, por meio do aumento do seu nível de produção, a possível resistência por parte dos cooperados poderia inviabilizar esse cenário.

Verifica-se que, para todos os itens listados, existe pelo menos um indicativo de influência de algum dos motivos avaliados. Os motivos mais citados foram a incompatibilidade com o foco estratégico da cooperativa e a não promoção do progresso econômico aos cooperados. Entretanto, verificam-se graus diferenciados de influência de cada um dos motivos listados. Os motivos que apresentam maior influência (muita) foram os relacionados à incompatibilidade com o foco estratégico da cooperativa (motivo 5) e com o histórico de produção da cooperativa (motivo 6) e possíveis resistências a mudanças por parte dos cooperados (motivo 7). Para os demais motivos, o grau de influência é considerado menor (pouca).
Para aprofundar a análise de como as cooperativas avaliam e gerenciam os riscos de mercado e a sua posição em relação aos cenários de portfólios eficientes gerados no estudo, foram conduzidas entrevistas semiestruturadas com gestores de quatro cooperativas agroindustriais do Paraná. O Quadro 3 apresenta a caracterização das cooperativas entrevistadas. $O$ roteiro da entrevista incluiu perguntas a respeito das práticas da cooperativa na gestão dos riscos de mercado, das percepções gerais sobre as propostas dos dois cenários de portfólios eficientes gerados na análise E-V e dos possíveis motivos que poderiam influenciar na decisão em não investir ou incentivar a produção de itens do agronegócio, com principal ênfase às commodities avaliadas no modelo. As respostas permitem avaliar qual seria a disposição das cooperativas para incentivar a diversificação e quais os motivos que mais influenciariam na inviabilidade desta prática.

Inicialmente, para investigar os motivos que poderiam influenciar na decisão em não investir ou incentivar a produção dos itens do modelo, foi solicitado ao respondente que indicasse quais seriam os motivos gerais. A pergunta foi feita de forma aberta. Neste primeiro passo, o motivo relacionado a restrições técnicas foi o mais citado. Em todas as citações não se verificou nenhum motivo relacionado a inconsistências entre os objetivos econômico e social das cooperativas. Todos os respondentes enfatizaram que, se houver viabilidade técnica e econômica, não há restrição quanto à produção de nenhum item que promova o progresso econômico dos cooperados e da cooperativa.

Quadro 3. Caracterização das cooperativas entrevistadas.

\begin{tabular}{|c|c|c|c|c|}
\hline Cooperativa & $\begin{array}{c}\text { Faturamento } \\
\text { em } \mathbf{2 0 0 7}(\mathbf{R} \mathbf{\text { mil)}})\end{array}$ & $\begin{array}{c}\text { Commodities do modelo que } \\
\text { integram o portfólio }\end{array}$ & Cargo do(s) respondente(s) & Auditor interno \\
\hline 1 & $3.466 .242,72$ & soja, milho, café e trigo & Assessor de auditoria interna & Administração e Ciências Contábeis \\
\cline { 3 - 5 } & $1.015 .569,11$ & $\begin{array}{c}\text { soja, milho, café, trigo e } \\
\text { laranja }\end{array}$ & Superintendente comercial & Administração \\
\hline 3 & $590.440,50$ & $\begin{array}{c}\text { soja, milho, feijão, trigo, } \\
\text { suínos e leite }\end{array}$ & Engenheiro Agrônomo & Diretor financeiro \\
\hline 4 & $206.000,00$ & $\begin{array}{c}\text { soja, milho, feijão, trigo e } \\
\text { bovinos }\end{array}$ & Engenheiro Agrônomo & \\
\hline
\end{tabular}


Na sequência, foi apresentado o mesmo conjunto de motivos investigados nos questionários enviados, apresentados no 10.764.1262. O objetivo foi investigar a possível influência de outros motivos não relacionados à viabilidade técnica e que são relacionados a características particulares da organização cooperativa e aos objetivos econômicos e sociais. Para a análise dos motivos foi perguntado: "existe algum item do agronegócio em que a cooperativa não estaria disposta a investir ou incentivar a produção em decorrência dos motivos abaixo?".

A análise desta parte da entrevista permitiu avaliar com maior detalhamento quais seriam alguns dos motivos que poderiam influenciar nas decisões de diversificação. Os principais motivos que poderiam implicar no fracasso das propostas visando maior diversificação, como principal resposta gerencial aos riscos de mercado, estão relacionados à viabilidade técnica e econômica, à experiência do histórico de produção das cooperativas e a possíveis resistências a mudanças por parte dos cooperados. Esses resultados estão em conformidade com o que foi levantado por meio dos questionários, discutidos acima. Segundo os respondentes alguns aspectos marcantes da doutrina cooperativa, como o compromisso e objetivos sociais, não exerceriam grande influência nas decisões relacionadas à diversificação.

Essas constatações corroboram com outra pesquisa realizada em cooperativas do estado do Paraná, que concluiu, ao entrevistar os cooperados, ser o aspecto econômico e comercial o principal motivo que leva o produtor rural a ingressar e se manter na cooperativa. Ou seja, a despeito da doutrina cooperativista, a cooperativa se posiciona a partir do que espera o cooperado, e este prioriza a manutenção e expansão da sua renda ao desenvolvimento social (SILVA e SALANEK FILHO, 2009).

\section{Conclusão}

Este artigo apresenta uma análise do portfólio de produção de commodities do agronegócio do estado do Paraná, as opções para melhorar a gestão dos riscos de mercado (análise retorno-risco) e a influência das cooperativas agropecuárias neste contexto. A análise empírica se deu, inicialmente, de forma exploratória, onde foram analisados dados secundários a respeito da produção agropecuária paranaense. As alternativas para o reposicionamento do portfólio de produção agropecuária do estado foram analisadas por meio da construção da fronteira de eficiência da análise E-V, gerada a partir do modelo de Markowitz. Verificou-se que algumas culturas teriam que apresentar uma substancial alteração em seus níveis de produção (para mais ou para menos), para que a margem bruta total tivesse um menor risco associado. Logo, com o desenvolvimento do modelo de análise E-V, foi possível levantar opções de portfólios eficientes que melhorariam a relação retorno-risco do agronegócio da região estudada, definindo, assim, dois cenários de melhoria dos riscos de mercado.

Os cenários avaliados relacionam as variações necessárias para partir do portfólio realizado em 2006 em direção aos portfólios eficientes. Entretanto, esses cenários levam em consideração somente a visão econômica e racional que embasa o modelo de Markowitz (análise E-V). Sob outras perspectivas, tais como a social ou a de estratégia de mercado, por exemplo, tais variações poderiam ser inviáveis. Ou seja, no contexto das cooperativas, a racionalidade econômica poderia conflitar com a racionalidade política e social, fortemente presente na doutrina cooperativa. Além disso, grandes alterações nas preferências de produção dos itens considerados na análise poderiam implicar em grandes investimentos na estrutura produtiva das cooperativas. Por conta disso, para avaliar a possível viabilidade das alterações propostas visando os cenários de portfólios eficientes, foram aplicados questionários e entrevistas às cooperativas paranaenses para verificar qual seria a aceitação por incentivos a mudanças visando esses cenários.

A análise do grau de participação das cooperativas agroindustriais paranaenses na produção das commodities mais representativas do agronegócio do estado sugeriu uma possível 
influência que estas organizações poderiam exercer em qualquer proposta de mudança. Entretanto, a análise dos resultados da pesquisa apresentada neste trabalho evidencia que, no contexto das cooperativas agroindustriais do Paraná, essas organizações não possuem um papel muito expressivo na influência das decisões sobre produção. Essas decisões são exercidas diretamente pelos produtores rurais que podem, ou não, ser influenciados por sugestões das cooperativas.

Verificou-se que, no contexto paranaense, os principais motivos que poderiam inviabilizar propostas de mudanças no portfólio, visando máxima eficiência econômica em termos de retorno-risco, estão relacionados ao foco estratégico da cooperativa e a resistências dos cooperados. Os motivos relacionados aos princípios doutrinários e aos objetivos econômicos e sociais da cooperativa, que efetivamente diferenciam este tipo de organização das empresas mercantis, receberam um grau menor de influência. Isto denota uma visão mais racional por parte das cooperativas, em detrimento das possíveis influências da doutrina cooperativista nas decisões. Neste caso, o processo decisório das cooperativas paranaenses está muito mais focado em critérios racionais (econômicos) do que políticos (sociais) quando se trata de assuntos relacionados à diversificação como meio para a gestão dos riscos de mercado. Logo, pode-se inferir que a tensão entre a racionalidade política e a racionalidade econômica na gestão cooperativa não é tão preponderante e não exerce muita influência na gestão dos riscos do agronegócio no Paraná.

Resumindo, embora os respondentes das entrevistas apontem de forma positiva algumas iniciativas que as cooperativas têm tomado para viabilizar opções aos produtores, não se verifica de forma geral uma disposição a mudanças nos portfólios de comercialização das cooperativas. Pode-se supor que o sucesso da estratégia de diversificação, como alternativa para a melhoria da relação retorno-risco do agronegócio, depende muito mais dos produtores do que do poder de influência das cooperativas.

Por fim, como as cooperativas são organizações que representam os interesses dos produtores rurais, além delas mesmas serem formadas por esses mesmos produtores, os objetivos econômicos das cooperativas podem servir de parâmetro para uma análise racional sobre opções viáveis de geração de valor no agronegócio. Isso pode motivar um maior desenvolvimento de pesquisas na área da Economia e Administração Rural, com o foco voltado às cooperativas e não apenas aos produtores rurais.

\section{Referências bibliográficas}

AGRIANUAL. Sazonalidade na Agricultura: Ganhando com a variação dos preços. Agrianual 1998: Anuário da Agricultura Brasileira. São Paulo: Instituto FNP, 1998.

ANDRETTA, G. C. Valor Bruto da Produção Agropecuária Paranaense de 2006. Curitiba: SEAB/DERAL/DEB, 2008. Disponível em http://www.seab.pr.gov.br, Acessado em 20/02/2008.

ANTONIALLI, L. M. Modelo de gestão e estratégias: o caso de duas cooperativas de leite e café de Minas Gerais. São Paulo, 2000. 238 f. Tese (Doutorado em Administração) Faculdade de Economia, Administração e Contabilidade, Universidade de São Paulo.

BIALOSKORSKI NETO, S. A. Agronegócio cooperativo. BATALHA, M. O. Gestão Agroindustrial, São Paulo: Atlas, v. 1, 2001.

EHRLICH, P. J.; MORAES, E. A. Engenharia econômica: avaliação e seleção de projetos de investimento. 6 . ed. São Paulo: Atlas, 2005.

FAO, Food and Agriculture Organization of the United Nations. Alternatives to improve negotiation and market access capabilities of small-scale rural entrepreneurs in Latin America. Rome: Agricultural Management, Marketing and Finance Service (AGSF), 2005. (Working Document).

FERREIRA, L. C. O dilema entre a especialização e a diversificação em uma cooperativa agrícola. Porto Alegre, 2002. 130 f. Dissertação (Mestrado em Administração) - Programa de Pós-graduação em Administração, Universidade Federal do Rio Grande do Sul.

FLATEN, O. et al. Comparing Risk Perceptions and Risk Management in Organic and Conventional Dairy Farming: Empirical Results from Norway. Livestock Production Science, v. 95, p. 11-25, 2005.

FRENKEL, M.; HOMMEL, U.; RUDOLF, M. (eds) Risk Management: Challenge and Opportunity. Berlin: Springer-Verlag, 2000. 
GOMES, A. G. Administração de Riscos: Como proteger-se contra riscos na agricultura. In: Agrianual 2000: Anuário da Agricultura Brasileira. São Paulo: Instituto FNP, 2000.

GUilhoto, J. J. M., FURTUOSO, M. C. O., BARROS, G. S. C. O agronegócio na economia brasileira - 1994 a 1999. Piracicaba: Relatório de Pesquisa ESALQ-USP/CEPEA, CNA, 2000.

HARDAKER, J. B. et al. Coping with risk in agriculture. CABI Publising, 2 ed., 2007.

HARDWOOD, J. et al. Managing Risk in Farming: Concepts, Research and Analysis. U.S. Department of Agriculture, Agricultural Economic Report no 774, 1999. Disponível em http://www.ers.usda.gov/publications/ aer774, acessado em 27/08/2008.

HAZELL, P. B. R. e NORTON, R. D. Mathematical Programming for Economic Analysis in Agriculture. New York: Macmillan Publishing Company, 1986.

HEIDELBACH, O. Efficiency of selected risk management instruments: An empirical analysis of risk reduction in Kazakhstani crop production. Germany, 2007. 232 f. Tese (Doutorado) - Faculty of Natural Sciences III at Martin Luther University Halle-Wittemberg. Disponível em http://www.iamo.de/dok/r_vol40.pdf, acessado em 01/08/08.

MANFREDO, M. R. e RICHARDS, T. J. Cooperative Risk Management, Rationale, and Effectiveness: The Case of Dairy Cooperatives. Agricultural Finance Review, v. 67, n. 2, p. 311-340, 2007.

MARKOWITZ, H. Portfolio selection. Journal of Finance, v. 7, n. 1, p. 77-91, 1952.

MOREIRA, V. R. Gestão dos riscos do agronegócio no contexto cooperativista. São Paulo, 2009. 208 f. Tese (Doutorado em Administração) - Escola de
Administração de Empresas de São Paulo, Fundação Getulio Vargas.

OCB, Organização das Cooperativas Brasileiras. Disponível em: www.brasilcooperativo.com.br, Acessado em: 03/04/2007.

OCEPAR, Sistema OCEPAR. Disponível em www. ocepar.org.br. Acessado em 18/11/2008.

PATRICK, G. R. et al. Risk perceptions and management responses: producer-generated hypotheses for risk modeling. Southern Journal of Agricultural Economics, v. 17, n. 2, p. 231-238, 1985.

PINOCHET-CHATEAU, R. et al. Changers in Risk Perception and Risk Management Strategies in New Zealand Dairy Farming. International Food and Agribusiness Management Association: 2005 World Food and Agribusiness Congress, 2005. Disponível em www.ifama.org/conferences/2005Conference/ Papers\&Discussions/1157_Paper_Final.pdf Acessado em: $27 / 08 / 2008$

SILVA, C. L. e SALANEK FILHO, P. Capital social y cooperativismo agropecuário: uma evalución do funcionamento de la cooperativa COPACOL/ PARANÁ/ BRASIL. Revista de Ciências Sociales (RCS), v. XV, n. 1, p. 50-67, FACES-LUZ, enero - abril 2009.

SHAPIRO, B. I.; BRORSEN, B. W. Factors Affecting Farmers' Hedging Decisions. North Central Journal of Agricultural Economics, v. 10, n. 2, p. 145-153, 1988.

USDA. Risk management. United States Department of Agriculture - 2007 Farm Bill Theme Papers. Disponível em: http://www.usda.gov/documents/ Farmbill07riskmgmtrev.pdf, Acessado em 27/08/2008.

ZEULI, K. A. New Risk-Management Strategies for Agricultural Cooperatives. American Journal of Agricultural Economics, v. 81, n. 5, p. 1234-1239, 1999. 